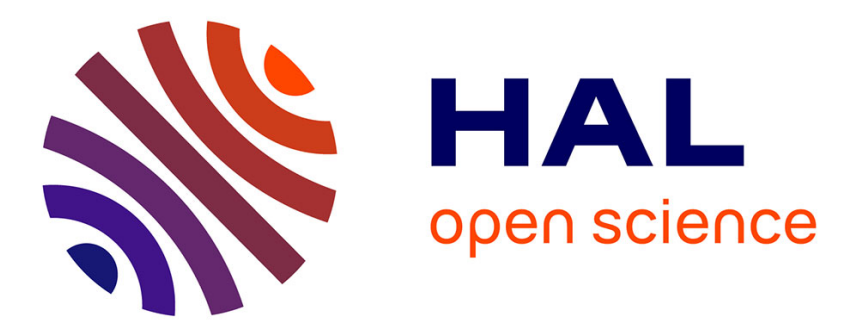

\title{
Using formal measures to improve maturity model assessment for conceptual interoperability
}

Gabriel S S Leal, Wided Guédria, Hervé Panetto, Erik Proper, Mario Lezoche

\section{To cite this version:}

Gabriel S S Leal, Wided Guédria, Hervé Panetto, Erik Proper, Mario Lezoche. Using formal measures to improve maturity model assessment for conceptual interoperability. 11th OTM/IFAC Enterprise Integration, Interoperability and Networking Workshop, EI2N, OM, Oct 2016, Kallithea, Rhodes, Greece. pp.47-56, 10.1007/978-3-319-55961-2_5. hal-01387780

\section{HAL Id: hal-01387780 \\ https://hal.science/hal-01387780}

Submitted on 26 Oct 2016

HAL is a multi-disciplinary open access archive for the deposit and dissemination of scientific research documents, whether they are published or not. The documents may come from teaching and research institutions in France or abroad, or from public or private research centers.
L'archive ouverte pluridisciplinaire HAL, est destinée au dépôt et à la diffusion de documents scientifiques de niveau recherche, publiés ou non, émanant des établissements d'enseignement et de recherche français ou étrangers, des laboratoires publics ou privés. 


\title{
Using formal measures to improve maturity model assessment for conceptual interoperability
}

\author{
Gabriel S. S. Leal ${ }^{1,2,3}$, Wided Guédria ${ }^{3}$, Hervé Panetto ${ }^{1,2}$, Erik Proper ${ }^{3}$, Mario Le- \\ zoche ${ }^{1,2}$ \\ ${ }^{1}$ CNRS, CRAN UMR 7039, France \\ ${ }^{2}$ Université de Lorraine, CRAN UMR 7039, Boulevard des Aiguillettes, B.P. 70239 F-54506 \\ Vandœuvre-lès-Nancy, France \\ \{gabriel.da-silva-serapiao-leal; herve.panetto; \\ mario.lezoche\} euniv-lorraine. fr \\ ${ }^{3}$ ITIS, TSS, Luxembourg Institute of Science and Technology (LIST), 5, avenue des Hauts- \\ Fourneaux, L-4362 Esch-sur-Alzette, Luxembourg \\ \{gabriel.leal; wided.guedria; erik.proper\}elist.lu
}

\begin{abstract}
To handle challenges such as globalization, new technologies and fast-changing environments, enterprises are progressively collaborating with others and becoming part of a Networked. In this context, Enterprise Interoperability (EI) is a crucial requirement that needs to be respected by enterprises when starting a collaborative relationship. As soon as this requirement is not achieved, EI becomes a problem that must be solved. To avoid these problems and consequently, take corrective actions on time, enterprises need to predict and solve potential problems before they occur. The Maturity Model for Enterprise Interoperability (MMEI) was proposed to assess the interoperability potential of an enterprise as well as to help enterprises evaluating the suitability of partners in an interoperability context. However, this method has some inconveniences such as the lack of formal definitions specifying the boundaries between each maturity level. Hence the objective of this paper is to formalize the MMEI maturity levels boundaries by defining formal measures. Finally, a case study is proposed to validate the defined measures.
\end{abstract}

Keywords: Networked Enterprise, Maturity Model, Enterprise Interoperability Assessment, Conceptual Interoperability, Formal Measures

\section{Introduction}

With the current fast changing environment, enterprises are progressively collaborating with each other and participating to a Networked Enterprise (NE) [1], to face challenges such as globalisation, new technologies, financial crisis, new markets, etc. Considering this NE context, we argue that one of the difficulties enterprises may face is the development of Enterprise Interoperability (EI) [2], [3] among their Collaborative Enterprise Systems (CESs) [4]. EI is a crucial requirement having to be verified by enterprises when starting a relationship with others to attain shared goals [1], [5]. As soon as this requirement is not achieved, interoperability becomes a problem that 
must be solved [1], [6]. To deal with this kind of problem, accurate evaluations can be performed to have a clear view of strengths and weaknesses of the considered NE regarding interoperability, at an early stage [1]. Some surveys and comparisons [4], [7], [8], [9], have been performed to evaluate existing interoperability assessment methods. Among these evaluation methods, the Maturity Model for Enterprise Interoperability (MMEI) [10], [11] proposes five maturity levels, describing the stages through which systems should evolve to reach higher completeness in the realisation of a given objective. It covers the three main interoperability aspects which are: Conceptual, Technical and Organizational interoperability [3]. MMEI was mainly conceived to assess the potentiality of an enterprise (or a system) to be interoperable with a possible future partner whose identity is not known at the moment of evaluation. Although the MMEI maturity levels are well structured, their definitions are based on qualitative measures i.e. the levels are subjective and the evaluation depends on the expertise of the assessors. This kind of measure has some inconveniences such as the lack of formal definitions specifying the boundaries between each maturity level and requires a very high level of expertise to apply these models in an industrial context [12]. A possibility raised by [4] to formalise the boundaries between each maturity level, is the use of quantitative measures (numeric values characterising the interoperations between CESs). Indeed, quantitative methods such as [13], [14], [15], [16], are capable of formalising and quantifying interoperability between known systems. However, they are not prepared and/or they do not have coherent value scales to be used with maturity models. Hence, the objective of this paper is to improve the MMEI interoperability evaluation by formalising its maturity levels boundaries. This will allow quantifying and qualifying the degree of interoperability between heterogeneous enterprises that need to participate in a NE. In this paper, we will focus only on the conceptual interoperability aspect. The technical and organisational aspects are out of the scope and will be investigated in future work. The formalisation of the MMEI conceptual maturity levels will be done by defining formal measures based on the quantitative methods. It will allow us to establish the transition between each maturity level by specifying thresholds (numeric values) for levels' boundaries. The proposed improvement is essential and will serve as one more step towards proposing a new approach for assessing enterprise interoperability within a $\mathrm{NE}$, using both qualitative and quantitative measures.

The rest of the paper is organised as follow - Section 2 presents the relevant related work. It is followed by Section 3 where the formal measures are proposed and the levels' boundaries are established. Section 4 illustrates a real case study based on an active NE in the field of marketing and communication in Luxembourg. The conclusion and future work are given in Section 5.

\section{Related work}

This section gives an overview of the Networked Enterprise Meta-Model (NEMO) [1], highlighting the core concepts of NE and interoperability, as well as, relationships between them. The different classifications and properties of enterprise interoperabil- 
ity assessment methods are also presented. Furthermore, the MMEI and its five maturity levels, as well as some formal measures proposed to assess the conceptual interoperability aspect, are brought forward.

\subsection{Networked Enterprise and Enterprise Interoperability}

NEMO [1] aims at providing a common understanding of the NE and interoperability concepts, based on a systemic approach. It defines a NE as: "a system composed of at least two autonomous systems (enterprises) that collaborate during a period of time to reach a shared objective". According to [17] and [18] enterprise systems are all sub-systems of an enterprise (e.g. Information systems, decisional systems, physical systems, etc.). Taking into account this view, [4] adopt the term Collaborative Enterprise System (CES) in order to represent the enterprise systems that collaborate with systems from other enterprises within the NE. Considering these perspectives, NEMO describes two views of interoperability: as a requirement that needs to be met when there is a need for at least two CESs to work together and as a problem when this requirement is not fulfilled. To describe the interoperability concepts within a NE, NEMO is based on the interoperability dimensions [1], [3]. Here, we present the three most important concepts that will be considered in the metrics proposition in section 3. The first one is the interoperability concerns representing the areas concerned by interoperability in an enterprise (business, process, service and data). The second, is conceptual interoperability aspect dealing with knowledge and information sharing among systems. Finally, the conceptual barriers concerning with the syntactic and semantic incompatibilities of information to be exchanged between systems. This kind of barrier can be related to enterprise models and the capacity of knowledge and semantic representation. More details about interoperability dimensions and other concepts can be found on [1], [3].

\subsection{Enterprise Interoperability Assessment}

In order to support enterprises to better interoperate with their partners within a NE, the interoperability between their CESs requires being assessed and continuously improved. According to [4], [10], the interoperability assessment methods can be classified based on the criteria depicted on Table 1.

Table 1. Interoperability assessment methods classification

\begin{tabular}{c|l|cc}
\hline \multicolumn{2}{c|}{ Criteria } & \multicolumn{2}{c}{ Classification } \\
\hline \multirow{3}{*}{$\begin{array}{c}\text { Method } \\
\text { properties }\end{array}$} & Structure & Levelling & Non-Levelling \\
& Used measure & Qualitative & Qualitative \\
& Type of interop. assessment & White Box & Black Box \\
& Interop. Aspects & Known partner & Unknown partner \\
\hline \multicolumn{2}{c}{ Inceptual } & Technical & Organisational \\
\hline
\end{tabular}

It is worth noting that interoperability is a non-bidirectional property [13]. It means that: Given two entities $\mathrm{A}$ and $\mathrm{B}$ and measuring their interoperability level $\mathrm{I}(\mathrm{x}, \mathrm{y})$ it is structurally coherent to find $I(A, B) \neq I(B, A)$. This structural property doesn't impact 
the evaluated methods because of its internal feature but it explains the behavioural aspects of the approached property concepts [4]. The following sections present the MMEI (a qualitative method) and quantitative methods.

\subsection{Maturity Model for Enterprise Interoperability (MMEI)}

MMEI has two primary purposes: (1) Define a common framework for assessing and measuring potential interoperability maturity, providing information for how far along an enterprise is regarding targeted maturity levels. (2) Provide information about 'best practices' that allow enterprises to improve their interoperability potential [10]. MMEI is a levelling method using qualitative measures and following a white box approach. It is mainly used when interoperation partners are unknown. MMEI defines five enterprise interoperability maturity levels: Unprepared, Defined, Aligned, Organized and Adaptive. Each maturity level is an instantiation of the main elements of an interoperability aspect with an evolution of the elements regarding the evolution of the level. When considering the conceptual interoperability aspects, these elements are: data models, service models, process models, business models, enterprise visions, strategies, objectives, policies, etc. Aligned to the enterprise maturity levels, MMEI identify five conceptual maturity levels that are: Incomplete, Modelled, Adhered, Mapped and Accommodate [19].

According to [11], in order to verify if two enterprises are interoperable, the concerned enterprises must assess their potential interoperability individually, using the MMEI model and then compare the obtained results. Having their maturity levels and identifying which criteria were not achieved from both sides, enterprises can foresee potential interoperability problems related to those non-achieved criteria.

\subsection{Quantitative methods for interoperability assessment}

Quantitative methods emphasize objective measurements and the statistical, mathematical, or numerical analysis of data collected through polls, questionnaires, and surveys, or by manipulating pre-existing statistical data using computational techniques [20]. Considering the enterprise interoperability domain, we identified the following methods dealing with the interoperability assessment: Based on a mathematical formalisation of the semantic relationship, Yahia et al. [13] proposed two measures, the maximal potential and the minimum effective interoperability. The iscore [14] intend to measure interoperability of complex networks using operational thread as its foundation and provides a single number measure of how well the systems interoperate along the thread. Barut et al. [15] propose a single 2-tuple index that encompasses both the depth of the information exchanged and used within the network as well as the richness and the amount of the information exchanged and used. The compatibility matrix [16] provides a matrix with 24 interoperability areas where the value " 1 " is attributed when an incompatibility is found. The degree of compatibility is given by the sum of incompatibilities found, where " 0 " means higher compatibility and " 24 " poorest compatibility between the considered systems. 


\section{Improving MMEI with formal measures}

In this section, our objective is to deal with the lack of formal definitions specifying the boundaries between each conceptual maturity level. First, we present the selected quantitative methods that will be used as basis to formulate the formal measures as well as the identified links between MMEI and those methods. Furthermore, the formal measures and the maturity levels' boundaries are presented.

\subsection{Linking MMEI and the selected quantitative methods}

Among the identified methods in section 2.4, we chose the approaches proposed by Yahia et al. [13] and Barut et al. [15] because they deal especially with the conceptual interoperability aspect. Moreover, both methods use a white box approach (where systems' inputs-outputs as well as their elements and structures are known) which facilitate the identification of problems in specific parts of a system. MMEI and the two selected approaches [13], [15], consider that interoperability is mainly concerned by the relationships and interactions between systems.

When dealing with the conceptual interoperability assessment, the Conceptual Models are the objects of evaluation. These models are composed by Semantic blocks that represent independent piece of knowledge containing their own minimal semantics. A Semantic Block is composed by Concepts which can be "Lexical" or "NonLexical" concepts [21]. Fig. 1 shows the links between MMEI concepts and the metamodel of semantic block structure [21] used by Yahia et al. [13] to determine their proposed measures. The specific MMEI elements are coloured in grey and the metamodel elements are coloured in white. The "Conceptual Model" is coloured in black as it's an element used from both approaches.

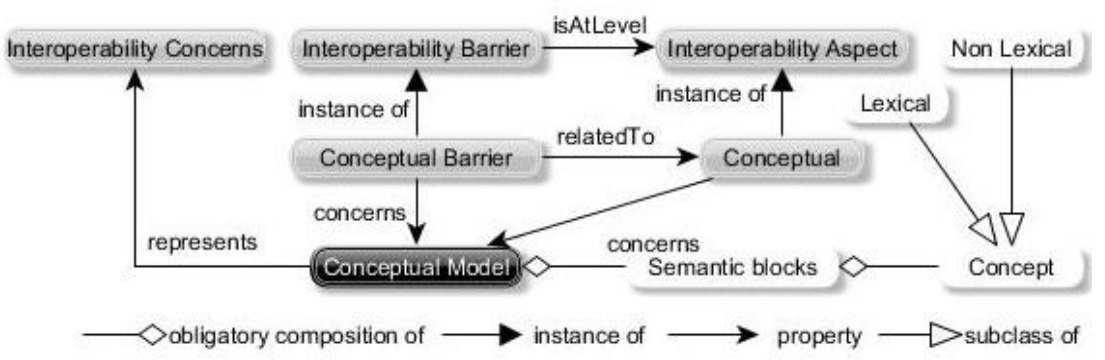

Fig. 1. Linking concepts from MMEI and Yahia et al. [13] approach.

Considering the studied measures to assess the conceptual interoperability, Barut et al. [15], provides two index: (1) the Information Extent describes how deep into the network that information is used. It can be compare with the potential interoperability index $(v)$ proposed by [13], which represents the maximal number of semantic relationships existing into the considered network. (2) The Information Intensity describes the richness and amount of the information used. It can be compared with the effective interoperability index $(\varepsilon)$ from [13], which verifies the number of mandatory 
concepts that are instantiated. Here, a set of mandatory concept $(M C)$ represents all the necessary and sufficient elements which make the conceptual model semantically coherent and understandable. On the contrary, a non-mandatory concepts (NMC) correspond to the non-mandatory roles and are only enriching the semantics of the CESs conceptual models.

\subsection{Defining maturity levels' boundaries}

Considering the five conceptual maturity levels and the index defined by [13], [15], we propose the boundary of each maturity level. These equations will be used to improve the step 4 (Assessment) from the MMEI methodology [10]. Before presenting the numerical values and the boundaries descriptions, we present the linguistic value' ranges and notations that we adopt to characterize if a level is achieved or not. It is based on [10] and [22] notations. The four defined values and their boundaries are: "Not Achieved (NA) $(0 \leq x \leq 15)$ ), "Partially Achieved (PA) $(15<x \leq 50)$ )", "Largely Achieved (LA) $(50<x \leq 85)$ ", "Fully Achieved (FA) $(85<x \leq 100)$. Based on that, we define the following equations:

$$
C A(\%)=\frac{C E S C+C E S a}{C E S c^{e}+C E S a^{e}}
$$

Where $C A(\%)$ is the ratio of the number of CESs' concepts and attributes identified and modelled over the total expected number of CESs' concepts and attributes. CESC is the number of modelled concepts from the concerned CES CESa is the number of modelled attributes from CES. $C E S c^{e}$ is the expected total number of modelled concepts from CES $C E S a^{e}$ is the total expected number of modelled attributes from CES.

$$
C L N L(\%)=\frac{C L+C N L}{C T^{e}}
$$

Where $C L N L(\%)$ is the ratio of the sum of Lexical and Non-Lexical Concepts from the considered CES over the total expected number of concepts from the CES. $C L$ is the number of Lexical concepts identified from CESs. $C N L$ is the number of Non-Lexical concepts identified from CES. $C T^{e}$ is the expected total number of concepts from the considered CESs $\left(C T^{e}=C E S c^{e}+C E S a^{e}\right)$.

$$
\operatorname{CMNM}(\%)=\frac{M C+N M C}{C T^{e}}
$$

Where $C M N M(\%)$ is the ratio of the sum of MC and NMC from both considered CESs over the total expected number of concepts from the considered CESs. The following equations are the same from Yahia et al. [13]. They represent the maximal potential interoperability (how many semantic relationships can be established within the considered network) and minimal effectiveness interoperability (the interoperability's quality).

$$
\text { Maximal potential }=\left(v_{1 \rightarrow 2}=\frac{\left|R_{C}^{2}\right|}{\left|R_{\text {Cexpected }}^{2}\right|}, \varepsilon_{1 \rightarrow 2}=\frac{\left|R_{C}^{2 \mathrm{e}}\right|}{\left|R_{C}^{2}\right|}\right)
$$




$$
\text { Minimal effectiveness }=\left(\mathrm{v}_{1 \rightarrow 2}^{e}=\frac{\left|R_{C}^{2 \mathrm{e}}\right|}{\left|R_{\text {Cexpected }}^{2}\right|}, \varepsilon_{1 \rightarrow 2}^{e}=100 \%\right)
$$

Where, $\left|R_{C}^{2}\right|$ is the set of the retrieved semantic relationships. $\left|R_{C}^{2 \mathrm{e}}\right|$ is a subset of $\left|R_{C}^{2}\right|$ that contains only MC. $\left|R_{\text {Cexpected }}^{2}\right|$ represents the set of the expected semantic relationships needed to ensure a full semantic interoperation.

Further, Table 2 describes the levels' boundaries and what need to be done to reach each one of them.

Table 2. Conceptual maturity levels and their boundaries.

\begin{tabular}{l} 
Level - Boundaries description \\
\hline Mevel 1 - Modelled: In order to reach this maturity level the considered conceptual models need \\
to be modelled. This is achieved by modelling the concepts and attributes from the concerned \\
CES and achieving CA = FA. \\
Level 2 - Adhered: The conceptual model need to be fully modelled to achieve this level of \\
maturity. The goal is reached using the standards and the translation of the Fact-oriented model- \\
ling. This is achieved by identifying and modelling the lexical and non-lexical concepts and their \\
attributes from the considered CES i.e. CLNL = FA and the entire mandatory and non- \\
mandatory concepts and their attributes from CES i.e. $C M N M=$ FA. \\
Level 3 - Mapped. This level represents the capability to perform Meta modelling for multiple \\
model mappings. Identifying and classifying all semantic relationships from the considered \\
semantic blocks within the conceptual models tackle this issue. All concepts from the CESs \\
must be identified and have all their potential semantics relationships recognized as well. This \\
can be verified if the Maximal Potential Interoperability (MPI) is achieved i.e. $(v)=(\varepsilon)=$ FA. \\
Level 4 - Accommodated. In order to reach this maturity level the business, processes, services \\
and data models must be adaptive. That is, they might be capable to dynamically adjust and \\
accommodate 'on the fly'. This can be verified if $\left(\varepsilon^{\mathrm{e}}\right)=100 \%$ and $(v)=(\varepsilon)=\left(v^{\mathrm{e}}\right)=$ FA. It worth \\
noting that when $(v)$ and $(\varepsilon)$ are equal to $100 \%$, the CES1 is fully interoperable to CES2.
\end{tabular}

\section{$4 \quad$ Case Study}

This section illustrates the evaluation of the proposed metrics using a real case study. The objective is to present the improvements brought to MMEI by implementing the formal measures and to prove that the metrics cover the lack of levels' boundaries formalization. The case study is based on The Factory Group (TFG) [23], an active $\mathrm{NE}$ in the field of marketing and communication in Luxembourg. TFG brings together five independent companies linked by their capital structure or by joint venture agreement. In this case study, we consider two enterprises from TFG: Concept Factory [24] and Exxus [25]. Following the MMEI methodology assessment [10], [11], the first step is to define the assessment scope which is to evaluate the interoperability between Exxus and Concept Factory, considering the collaborative process responsible for planning future collaborative tasks. The information used to define the scenario was gathered through interviews and analysis of provided documents by the different enterprises. The selected interviewees are members of the board of directors of each considered enterprise. Based on the gathered information, we have first applied the MMEI criteria assessment in each concerned enterprises individually and we have crossed the obtained results from each one of them in order to identify which potential incompatibilities may appear when the interoperation starts. One of the main points in 
this case study is that according to the gathered information, the collaborative process responsible for planning future collaborative tasks is not modelled. This process was introduced when the new responsible was chosen (the Concept Factory Account Director). This leads to work on the tacit knowledge [21]. In the specific case study the knowledge is trapped in employees mind. The assessors, working to structure and to understand the level of knowledge possessed, realised that despite the process was not modelled in both enterprises, most employees knows what need to be done i.e. which steps they need to take to realize the process. Table 3 shows some of the obtained results for each enterprise, considering the first MMEI maturity level (Modelled).

Table 3. Simplified view of MMEI raiting. "L" stands for Level. "NA" stands for Not Achieved, "PA" for Partially Achieved, "LA" for Largely Achieved and "FA" for Fully Achieved.

\begin{tabular}{|c|c|c|c|c|c|c|c|c|c|}
\hline \multirow[t]{2}{*}{$\mathbf{L}$} & \multirow{2}{*}{ Activities to evaluate } & \multicolumn{4}{|c|}{ Concept Factory } & \multicolumn{4}{|c|}{ Exxus } \\
\hline & & NA & PA & LA & FA & NA & PA & LA & FA \\
\hline 1 & $\begin{array}{l}\text { Process models are explicitly defined and } \\
\text { documented (objective evaluation) }\end{array}$ & $\mathrm{X}$ & & & & $\mathrm{X}$ & & & \\
\hline 1 & $\begin{array}{l}\text { Process models are explicitly defined and } \\
\text { documented (assessors perception) }\end{array}$ & & & $\mathrm{X}$ & & & & $\mathrm{X}$ & \\
\hline
\end{tabular}

Even though the process are not modelled in both enterprises, the assessors considered that both enterprises largely achieved the level 1 . The assessment was based on the tacit knowledge presented by the interviewees and their perception considering the day-of-day from employees. However, the linguistic values assigned to those criteria are subjective, as it depends of the expertise and considerations of the assessors. Another inconvenience related to the dependence of the assessor's expertise, is that results may vary from among assessors. Using the same gathered information, we use the proposed measures, in the assessment step, to verify if the concepts and attributes from the processes conceptual models are really identified. The obtained results are the following: $\mathrm{CA}_{\text {ConceptFactory }}=40 \%(\mathrm{PA})$ and $\mathrm{CA}_{\text {Exxus }}=0 \%(\mathrm{NA})$. The assessment takes in count mainly the available conceptual models from both enterprises. Concept Factory has some data models that are used as basis to gather the needed information in order to plan the weekly tasks but the other process activities are not modelled nor documented. Exxus does not have any available conceptual model concerning this kind of process. Having this numeric values, allow assessor to identify what need to be done to achieve a given maturity level. For example, in this case study, Concept Factory need to model the remaining $60 \%$ concepts and attributes related to the assessed process and Exxus need to model the entire process. A possible solution could be both enterprises realize the process modelling together, taking into account what the "Concept Factory" already has.

\section{$5 \quad$ Conclusion and Future Work}

In this paper, we have proposed an improvement of the Maturity Model for Enterprise Interoperability by defining formal measures to identify the maturity levels boundaries. It has been asserted that despite being well structured, the boundaries of MMEI maturity levels lack formalization. Although, it is clear which requirements are need- 
ed to reach a given maturity level, the assessment depends on subjective criteria. Formal measures have been identified as a possibility to fulfil this gap. Furthermore, a brief analysis considering the MMEI conceptual aspect and quantitative methods was done. Based on the related work, we proposed to improve the MMEI conceptual interoperability assessment by establishing formal measures in order to define each maturity level boundaries. A real case study of an active NE in Luxembourg has been studied to validate the proposed approaches, by illustrating the interoperability evaluation between two enterprises. As future work, we intend to improve MMEI technical and organisational aspects, by applying quantitative evaluation methods. Furthermore, we intend to develop an Interoperability Assessment Approach for Networked Enterprise context. This approach will be part of a Framework for the Networked Enterprise Interoperability that will serve as basis to the development of a decision-support system for preventing and solving interoperability problems in the NE context.

\section{Acknowledgements}

This work has been conducted in the context of the PLATINE project (PLAnning Transformation Interoperability in Networked Enterprises), financed by the national fund of research of the Grand Duchy of Luxembourg (FNR), under the grant C14/IS/8329172.

\section{References}

1. Leal, G., Guédria, W., Panetto, H., Proper, E.: Towards a Meta-Model for Networked Enterprise. 21st international conference on exploring modelling methods for systems analysis and design (EMMSAD 2016), Jun 2016, Ljubljana, Slovenia. Springer, 248, pp.417431, Enterprise, Business-Process and Information Systems Modeling, Lecture Notes in Business Information Processing (2016)

2. Institute of Electrical and Electronics Engineers. IEEE standard computer dictionary: A compilation of IEEE standard computer glossaries. (1990)

3. ISO: Advanced automation technologies and their applications - Part 1: Framework for enterprise interoperability, International Organization for Standardization, ISO 11354, ISO/TC 184/SC 5. (2011)

4. Leal, G., Guédria, W., Panetto, H., Lezoche, M. Towards a comparative analysis of interoperability assessment approaches for collaborative enterprise systems. In 2016 ISPE International Conference on Transdisciplinary Engineering Proceedings, Curitiba, Brazil. (2016) (Accepted - in press)

5. Mallek, S., Daclin, N., Chapurlat, V.: The application of interoperability requirement specification and verification to collaborative processes. In Computers in industry, vol. 63, issue 7, pp. 643-658. (2012)

6. Naudet, Y., Latour, T., Guedria, W., Chen, D.: Towards a systemic formalisation of interoperability. In: Computers in Industry, vol. 61, Issue 2, Integration and Information in Networked Enterprises, pp. 176-185. (2010) 
7. Ford, T., Interoperability Measurement. Dissertation, Air Force Institute of Technology, Wright-Patterson AFB, OH, (2008)

8. Panetto, H. Towards a Classification Framework for Interoperability of Enterprise Applications. In: International Journal of Computer Integrated Manufacturing, Taylor \& Francis: STM, Behavioural Science and Public Health Titles, vol. 20, issue 8, pp.727-740. (2007)

9. Guedria, W., Naudet, Y., Chen, D. Interoperability maturity models - survey and comparison, in: Proceedings of 3th International Workshops on Enterprise, Interoperability and Networking (EI2N 2008). OTM Confederated International Workshops and Posters, Monterrey, Mexico, LNCS 5333, November, Springer, pp. 273--282. (2008)

10. Guedria, W., Naudet, Y., Chen, D. Maturity model for enterprise interoperability, In Enterprise Information Systems, vol. 9, issue 1, pp. 1-18. (2015)

11. Guedria, W., Naudet, Y., Chen, D. Maturity model as decision support for enterprise interoperability, On the Move to Meaningful Internet Systems: OTM 2011 Work-shops Lecture Notes in Computer Science 7046. Pp. 604-608. (2011)

12. Panetto, H., Zdravković, M. Jardim-Goncalves, R., Romero, D., Cecil, J. New Perspectives for the Future Interoperable Enterprise Systems. Computers in Industry, Elsevier, Special Issue: "Future Perspectives on Next Generation Enterprise Information Systems: Emerging Domains and Application Environments", 79, pp.47-63. (2016)

13. Yahia, E., Aubry, A., Panetto, H. Formal measures for semantic interoperability assessment in cooperative enterprise information systems. In: Computers in Industry vol. 63, issues 5, pp. 443-457 (2012)

14. Ford, T., Colombi, J., Graham, J., Jacques, D. The Interoperability Score. In: Proceedings of the 5th Annual Conference on Systems Engineering Research. Hoboken, N.J., (2007)

15. Barut, M., Faisst, W., Kanet, J.J.. Measuring supply chain coupling: an information system perspective. European Journal of Purchasing and Supply Management 8, $\mathrm{n}^{\circ} 3$ : 161-171. (2002)

16. ATHENA Integrated Project. Guidelines and Best Practices for Applying the ATHENA Interoperability Framework to Support SME Participation in Digital Ecosystems, ATHENA Deliverable DA8.2, January, (2007)

17. Chen, D., Vallespir, B., Doumeingts, G. : "GRAI integrated methodology and its mapping onto generic enterprise reference architecture and methodology", Computers in Industry, Vol.33, pp.387-394, (1997)

18. Naudet, Y., Guedria, W.: Extending the Ontology of Enterprise Interoperability (OoEI) using Enterprise-As-system Concepts. In: I-ESA '14 Proceedings of the International Conference on Interoperability for Enterprise Software and Applications. (2014).

19. Guédria, W., Chen, D., \& Naudet, Y.. A Maturity Model for Enterprise Interoperability. In R. Meersman, P. Herrero \& T. Dillon (Eds.), Lecture Notes in Computer Science, pp. 216225. (2009)

20. Babbie, E. The practice of social research (14th ed.). Wadsworth Publishing; 13th edition (2012).

21. Lezoche M., Yahia E., Aubry A., Panetto H., Zdravkovic M. Conceptualising and structuring semantics in Cooperative Enterprise Information Systems Models. Computers in Industry, Elsevier, 63 (8), pp.775-787. (2012)

22. Rout, T. P., El Emam, K., Fusani, M., Goldenson, D. and Jung, H. W. "SPICE in Retrospect: Developing a Standard for Process Assessment." Journal of Systems and Software 80 (9): 1483-1493 (2007)

23. The Factory Group, http://www.thefactorygroup.com/

24. Concept Factory, http://conceptfactory.lu/

25. Exxus, http://exxus.lu/ 